\title{
Does Obesity Lead to Sciatic Pain: A Comparative Study
}

\section{IJCRR}

Section: Healthcare

Sci. Journal Impact

Factor: 6.1 (2018)

ICV: 90.90 (2018)

(c) (7) (3)

Copyright@IJCRR

\section{Milind Abhimanyu Nisargandha ${ }^{1}$, Shweta Dadarao Parwe ${ }^{2}$}

\author{
'Department of Physiology, Ashwini Rural Medical College, Hospital \& research Centre Khumbhari Solapur, Maharashtra University of \\ Health Sciences, Nashik Maharashtra, India; ${ }^{2}$ Department of Panchakarma, Mahatma Gandhi Ayurved College, Hospital \& Research \\ Centre, Salad (H), Wardha, Datta Meghe Institute of Medical Sciences (DU), Nagpur, Maharashtra, India.
}

\section{ABSTRACT}

Background: Obesity leads musculoskeletal problem which is affecting the Spinal disorder are related to low back pain. This is more affected in obese people with the impact of workload. The Sciatica is a clinical condition characterized by severe pain started from the low back region and radiating down along the course of the leg. Very few studies were conducted in the Indian population. Therefore, an attempt has made to study the NCV in obese patients of sciatica pain common. To the observer the relation of overweight and obesity with sciatica pain.

Methods: The study was carried in the physiology department in which we have included 100 patients, which was suffering sciatica. The patients were evaluated for the straight leg raising test (SLR) positive. These patients were referred to the NCV based on BMI for rule out the obesity. NCV study was done on RMS EMG EP Mark-II.

Result: The mean value of Motor nerve conduction velocity was $51.79+3.46$ in a normal subject and it was $48.02+5.17$ on the in an obese subject which was significantly decreased.

Conclusion: We conclude that obese patients are increases risk of radiating pain which is specific in men and women. Taking into consideration the recent situation of worldwide obesity we emphasis on the does obesity lead to sciatic pain. We found sciatic neuropathy in obese patients.

Key Words: BMI, Nerve conduction velocity, Overweight, Obesity, Sciatica, Straight leg rising test

\section{INTRODUCTION}

Obesity is the major problem in worldwide which is associated with a different complication like cardiovascular disease, diabetes mellitus, hypertension atherosclerosis, now a day's obesity is correlated with musculoskeletal problems. ${ }^{1}$ Overweight and obesity are correlated to accelerated the risk of lower back pain. ${ }^{2}$ Many patients' complaints regarding the low back pain (LBP). Sciatic neuropathy is one of the lower extremities most common peripheral neuropathy. One of the most common sciatic neuropathy presentations is drop in the foot. Because weakness of the ankle dorsiflexion, with or without sensory impairment of the lower extremity, can also be associated with several other clinical syndromes, careful evaluation is necessary before confirming a diagnosis of sciatic neuropathy. Electrodiagnostic testing is one important device for confirmation of suspect sciatic neuropathy and in assessing the potential for nerve function recovery. ${ }^{3,4}$
Few studies specifically examine sciatica, but some low back pain studies include data on sciatica prevalence, risk factors, and natural history. Low back-related leg pain, or sciatica, is one of the most common variations of low back pain. ${ }^{5}$ Sciatica is known in the literature through a variety of terms such as lumbosacral radicular syndrome, radiculopathy, nerve root pain, and nerve root trapping or irritation. There is controversy over the use of sciatica as a term in clinical and research contexts. ${ }^{6,7}$ Sciatic pain is generally defined as pain radiating to the leg, normally below the knee and into the foot and toes. As with low back pain, sciatica is a symptom rather than a specific diagnosis, ${ }^{8}$ but lumbar disk herniation and lumbar canal or foraminal stenosis are typical pathologies that may cause sciatic pain. ${ }^{9}$

Sciatic patients usually have major pain which is lower back pain radiating to leg. These patients having more disability and they are irregular for the work due to the pain. ${ }^{10,11}$

\section{Corresponding Author:}

Dr. Shweta Dadarao Parwe, Department of Panchakarma, Mahatma Gandhi Ayurved College, Hospital \& Research Centre, Salad (H), Wardha, Datta Meghe Institute of Medical Sciences (DU), Nagpur, Maharashtra, India; Contact: +919403142270; Email: drshwetaparve@gmail.com, shweta.parwe@dmimsu.edu.in

ISSN: 2231-2196 (Print)

Received: 19.06 .2020
ISSN: $0975-5241$ (Online)

Revised: 25.07 .2020
Accepted: 27.08 .2020
Published: 07.12 .2020 
LBP was longer duration is considered as a mainly neurological cause. However, in the past decade, many authors reported that socioeconomic and work-related factors which were not previously investigated may contribute to LBP. Few studies of sciatic pain exist. Therefore, assessing overweight and obesity leads to Nerve conduction studies in the patients of sciatic involvements. ${ }^{12}$ We undertake the present study, to find out any relation in between overweight and obese subjects suffering from sciatica pain.

\section{MATERIALS AND METHODS}

This study was conducted at MGM college and hospital Aurangabad. The patients having LBP with overweight and obese are categories initially and send for the neurophysiology lab in the hospital for Nerve conduction study. These selected patients' routine clinical examination was carried out and noted all anthropometric parameters. The patient having mild, moderate, severe pain which is radiating to legs were included in our study.

Anthropometric measurements: The height and weight were measured after the recruitment of the subjects in the study. In standing, position height was measured and weight is in $\mathrm{kg} \cdot{ }^{13,14}$ according to the weight and height BMI was calculated as weight $/ \mathrm{height}^{2}\left(\mathrm{~kg} / \mathrm{m}^{2}\right)$. Other variables like waist, hip circumferences were measured and hip waist ratio was calculated. ${ }^{15}$

Cardiovascular parameter: The pulse rate was recorded by manually, the pulse was examined with three fingers of the right hand over the subject of the radial artery with three fingers, in semi flexed wrist with the distal figure for obliterating the retrograde pulsation. Pulse rate was the count for one minute. In the supine position, the blood pressure was noted with a sphygmomanometer (Diamond) on the arm at the heart level. ${ }^{16}{ }^{17}$

MGM- ECRHS Approval Letter - MGM-ECRHS/2015 $/ 07$

\section{Study Design: Case-Control}

Sample Size: 100

Period of Study: Two year

Study Population: OPD/IPD overweight Patients Lower Back Pain (LBP) willing for investigation.

Study Area: Mahatma Gandhi Medical College, Aurangabad

Inclusion criteria:

- Reproductive age group $>20$ to 60 years

- Patients having Sciatica

- LBP (low back pain
- SLR (straight Legs Rising) test Positive

\section{Exclusion criteria}

- Surgical intervention.

- Fracture in pelvic

\section{Electrophysiological methods}

Nerve conduction study was done on RMS EMG EP MarkII. For Motor nerve study, duration was kept at $200 \mu$ s, the filter was between $2 \mathrm{~Hz}$ to $10 \mathrm{kHz}$ and sweep speed was 5 $\mathrm{ms} / \mathrm{D}$ for lower limb and at $100 \mu \mathrm{s}, 2 \mathrm{~Hz}-5 \mathrm{kHz}, 5 \mathrm{~ms} / \mathrm{D}$. Parameters studied for motor nerves were distal motor latency (DML), amplitude and conduction velocity (CV). ${ }^{18}$

Straight Leg Rising Test (SLRT): This is the most important diagnostic sign in the patients of Sciatica. The SLRT was carried out with the patient at the supine position. The leg affected with sciatica was raised passively, with the patient relaxed and the knee in full extension. When the patient started to feel discomfort, the elevation of the leg was stopped, and the elevation angle and amount of pelvic movement were registered. The patient was then asked to indicate how the pain and paraesthesia were distributed. The foot was dorsiflexed with the leg in the raised position, and the neck was flexed and the effect of this was also documented. Another side straight-leg raising was carried out. ${ }^{19}$ In this study, we categorized the SLR in the following Grade

\begin{tabular}{lcc} 
& SLR Grade & Degree of Angle \\
Normal & 0 & $90-75$ \\
Mild & 1 & $75-65$ \\
Moderate & 2 & $65-55$ \\
Sever & 3 & $55-45$ \\
Sever & 4 & $45-35$ \\
\hline
\end{tabular}

\section{RESULTS}

The present work was carried out in the Physiology department at Mahatma Gandhi Medical College to analyze the role of overweight and obesity may affect sciatica.

\section{Demographic characteristics of Subject}

The total number of subjects recruited in this study was 104 among these three Patients' dropout due to absenteeism and One is not willing for performing the Nerve Conduction Study. Total 100 patients were selected for this study, out of that $68 \%$ population of patients (68) were female and $32 \%$ population (32) were male in graph. ${ }^{1}$ In table 1 straight leg raising test and its grades were categorised based on the degree of angle. The number of patients was distributed in it.

Table 2 shows anthropometric values, the mean value of anthropometric parameters weight, height and BMI was 75.86 $\pm 8.80,156.96 \pm 9.76$ and $30.96 \pm 4.04$ respectively. Table 3 
shows the mean values of Demographic parameters such as pulse, systolic and diastolic blood pressure and Chest, Waist, Hip Circumference and their ratio. The mean value of Motor nerve conduction Velocity in the normal subject was $51.79 \pm$ 3.46 and the motor nerve conduction velocity of the sciatic patient was $48.02 \pm 5.17$ on the affected shows in decreased value in table 4 , which was statistically significant.

\section{DISCUSSION}

Electrodiagnostic tool used to test the functioning of nerves, particularly the ability of transmission of the electrical stimulus. NCV studies can understand the degree of demyelination and axonal loss in examined nerve segments. Demyelination of a nerve results in prolonged conductive duration (decreased conductive velocity), while axonal impairment typically results in impairment of nerve fibres and potential strength of the muscle. The assessment of the electrodiagnostic study of nerve conduction is measured by four criteria, i.e., latency, Amplitude, Duration and velocity of the evoked potential. Out of which Motor nerve conduction Velocity is the important parameter for the involvement of nerve. Table 1 shows the gender-wise distribution of Patients involved in the Sciatica.

Table 2 shows the Straight Leg Rising Test with Grade and number of Patient involved in Nerve conduction study as per their severity. In another study by Michael et al (1974) observed the form of pain induced by passive SLR fell into three precise groups. ${ }^{19}$ Table No 2 shows Anthropometric Parameters like weight, height and BMI of sciatic subjects There is a likely causal relationship between body height and sciatic risk, but height isn't necessarily predictive of other types of low back pain. Obesity, smoking, psychological distress and poor general health also carry an increased risk of low back pain but is questionable about their possible association. Although none of the suspected risk factors can be identified as being scientifically well investigated. ${ }^{20}$

This study is aimed at deriving obesity lead to Nerve conduction velocity in a specific regional population that closely correlates to the demographic outline of the patients of sciatica being considered. In this study, obesity leads to Sciatic nerve conduction involvement found in conduction velocity significantly decreases. NCV tests may recognize the level of demyelination and neuronal loss in examined nerve parts. Demyelination of a nerve leads to increased delivery times. A similar finding was observed in "obese may also interfere with the nutrition of the intervertebral discs, leading to an impaired healing process. In a 3-year follow-up study of sciatica patients. ${ }^{21,22} \mathrm{BMI}$ was the strongest interpreter of incident lumbar artery occlusion, which also suggests that impairment of nutrition can be one of the pathways of obesity's relationship with sciatica.
Obesity supports establish chronic, low-grade inflammation by releasing inflammatory mediators from excess adipose tissue. ${ }^{23}$ Chronic inflammation associated with obesity may lead to the development of sciatica or to the develop the symptoms of sciatic. Leptin is one of the major constituents of adipocyte-derived adipokines which raised the serum leptin which is correlated to obesity and leads to BMI-independent knee arthritis. ${ }^{24}$ Leptin is estimated of involving the reorganization of nucleus pulposus cells cytoskeletons, ${ }^{25}$ but the fat tissue-derived leptin in the association between sciatica and obesity. Leptine is the key substance for controlling homeostasis of body weight and energy balance. The gene, coding protein which consists of 165 amino acid is called Leptine which produce adipocytes. The obese people often show hyperleptinemia this may cause by the post-receptor disorder. It is supposed to absolute and relative leptine deficiency in obese people

\section{CONCLUSION}

An electrodiagnostic test is an important tool used to test the functioning of nerves, speciallyto check the of conduction of electrical stimulus. NCV studies can early recognize demyelination and neuronal loss. Due to demyelination prolong conduction velocity observed. We concluded that, early detection of demyelination and neuronal loss helpful for avoiding sciatic pain in an obese person. This also shows comparative data of the patient having sciatic pain with the normal subject.

\section{ACKNOWLEDGMENT}

We the authors acknowledge help from the Dr. Pramod Shinde and Dr. Sangeeta Phatale for their continuous support throughout the work. The authors are also a deep sense of gratitude to Dr. Wankhede SG professor for his guidance during entire work. We are thankful to all authors of journals and articles from where the literature for the article was reviewed and discussed.

\section{Source of funding: No}

Conflict of Interest: There is no conflict in this article.

\section{REFERENCES}

1. Schulte PA, Wagner GR, Ostry A, Blanciforti LA, Cutlip RG, Krajnak KM, et. al.Work, obesity, and occupational safety and health. Am J Public Health 2007 Mar;97(3):428-36.

2. Atlas SJ, Nardin RA. Evaluation and treatment of low back pain: An evidence-based approach to clinical care. Muscle Nerve 2003 Mar;27(3):265-84.

3. Baima J, Krivickas L. Evaluation and treatment of peroneal neuropathy. Curr Rev Musculoske Med 2008 Jun;1(2):147-53. 
4. Nisargandha MA, Parwe SD, Wankhede SG, Deshpande VK. Comparison of nerve conduction studies on affected and nonaffected side in the patients of sciatica. Int J Basic Appl Physiol 2020;9(1):1.

5. Manchikanti L. Epidemiology of low back pain. Pain Physician 2000 Apr;3(2):167-92.

6. Meknas K, Johansen O, Kartus J. Retro-trochanteric sciaticalike pain: current concept. Knee Surgery, Sports Traumatology, Arthroscopy 2011 Nov;19(11):1971.

7. Wilde VE, Ford JJ, McMeeken JM. Indicators of lumbar zygapophyseal joint pain: a survey of an expert panel with the Delphi technique. Physical Therapy 2007 Oct;87(10):1348-61.

8. Nisargandha MA, Parwe S, Wankhede SG, Shinde PU, Phatale SR, Deshpande VK. Nerve Conduction Studies on Patients of Sciatica. Int J Biol Med Res 2017;8(3):6050-2.

9. Konstantinou K, Dunn KM. Sciatica: A review of epidemiological studies and prevalence estimates. Spine 2008 Oct;33(22):2464-72.

10. Cherkin DC, Deyo RA, Wheeler K, Ciol MA. Physician variation in diagnostic testing for low back pain. Who you see is what you get. Arthritis Rheumat 1994 Jan;37(1):15-22.

11. Bratton RL. Assessment and management of acute low back pain. Am Family Physician 1999 Nov;60(8):2299.

12. Megerian JT, Kong X, Gozani SN. The utility of nerve conduction studies for carpal tunnel syndrome by family medicine, primary care, and internal medicine physicians. J Am Board Family Med 2007 Jan;20(1):60-4.

13. Shiely F, Hayes K, Perry IJ, Kelleher CC. Height and weight bias: the influence of time. PloS one 2013;8(1).

14. Norton K, Whittingham N, Carter L, Kerr D, Gore C, MarfellJones M. Measurement techniques in anthropometry. Anthropometric 1996;1:25-75.

15. Willett WA, Hu FR. Anthropometric measures and body composition. Nutr Epidemiol 2013 Jan 1;15.

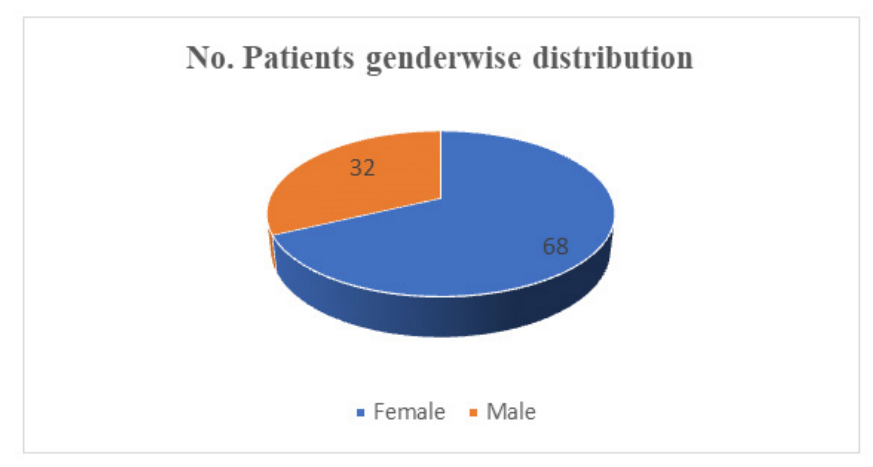

Figure 1: Gender wise distribution of research participants.

Table 1: Straight Leg Rising Test with Grade and number of Patient involved in sciatica.

\begin{tabular}{llc} 
Sr. No. & SLR GRADE & No. of sciatica Patients (50) \\
1. & Mild & 3 \\
2. & Moderate & 4 \\
3. & Sever Grade-1 & 25 \\
4. & Sever Grade-2 & 18 \\
\hline
\end{tabular}

16. Ogedegbe G, Pickering T. Principles and techniques of blood pressure measurement. Cardiol Clinics 2010 Nov;28(4):571-86.

17. Jafar TH, Islam M, Poulter N, Hatcher J, Schmid CH, Levey AS, Chaturvedi N. Children in South Asia have higher body mass-adjusted blood pressure levels than white children in the United States: A comparative study. Circulation 2005 Mar;111(10):1291-7.

18. Pawar SM, Taksande AB, Singh R. Effect of body mass index on parameters of nerve conduction study in Indian population. Indian J Physiol Pharmacol 2012;56(1):88-93.

19. Edgar MA, Park WM. Induced pain patterns on passive straightleg raising in lower lumbar disc protrusion: a prospective clinical, and operative study in fifty patients. The Journal of bone and joint surgery. J Bone Joint Surg 1974 Nov;56(4):658-67.

20. Heliövaara M. Risk factors for low back pain and sciatica. Annals of medicine. 1989 Jan 1;21(4):257-64.

21. Karppinen J, Kurunlahti M, Taimela S, Haapea M, Vanharanta $\mathrm{H}$, Tervonen O. Determinants of lumbar artery occlusion among patients with sciatica: a three-year follow-up with magnetic resonance angiography. Euro Spine J 2005 Sep;14(7):664-70.

22. Berg AH, Scherer PE. Adipose tissue, inflammation, and cardiovascular disease. Circul Res 2005 May;96(9):939-49.

23. Dumond H, Presle N, Terlain B, Mainard D, Loeuille D, Netter P, et. al. Evidence for a key role of leptin in osteoarthritis. Arthri Rheumat 2003 Nov;48(11):3118-29.

24. Harwood Jr HJ. The adipocyte as an endocrine organ in the regulation of metabolic homeostasis. Neuropharmacology 2012 Jul;63(1):57-75.

25. Li Z, Shen J, Wu WK, Yu X, Liang J, Qiu G, Liu J. The role of leptin on the organization and expression of cytoskeleton elements in nucleus pulposus cells. J Orthop Res 2013 Jun;31(6):847-57.

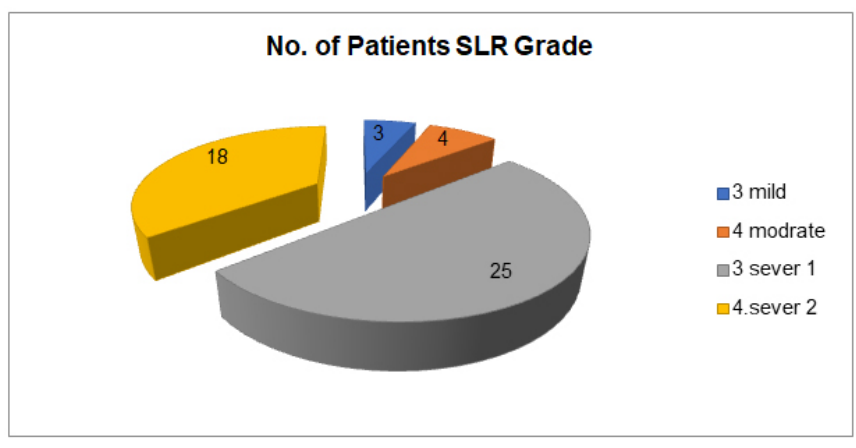

Figure 2: Straight Leg Rising Test with Grade and number of Patient involved in Nerve conduction study.

\section{Table 2: Anthropometric Parameters.}

\begin{tabular}{lll} 
Weight & Height & BMI \\
$75.86+8.80$ & $156.96+9.76$ & $30.96+4.04$ \\
\hline
\end{tabular}




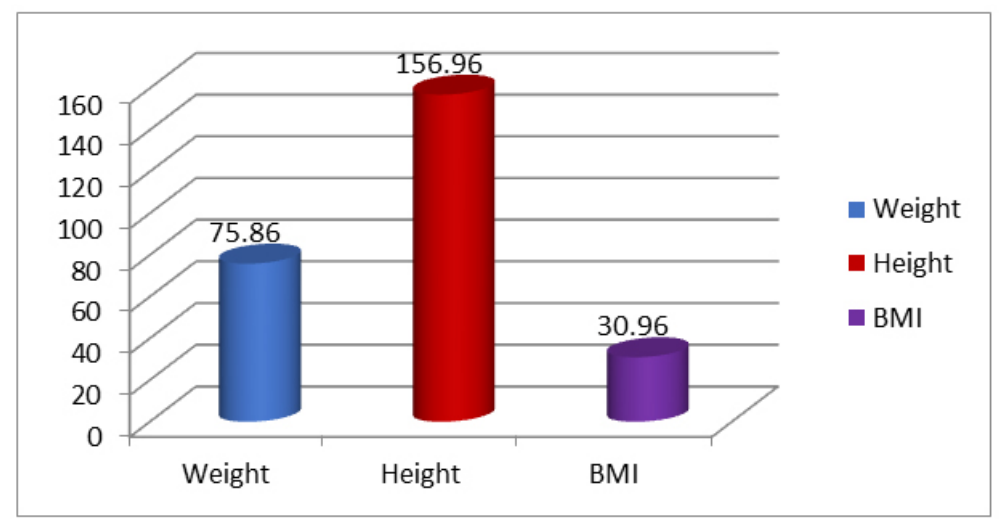

Figure 3: Anthropometric Parameters

Table 3: Cardiovascular Parameters

\begin{tabular}{|c|c|c|c|c|c|c|}
\hline & 2. Bloo & ressure & 3. & 4. & 5. & 6. \\
\hline Pulse & Systolic B P & Diastolic B P & $\begin{array}{l}\text { Chest circumfer- } \\
\text { ence }\end{array}$ & $\begin{array}{l}\text { Waist Circumfer- } \\
\text { ence }\end{array}$ & $\begin{array}{l}\text { Hip circumfer- } \\
\text { ence }\end{array}$ & WHR \\
\hline Mean + SD & Mean + SD & Mean + SD & Mean + SD & Mean + SD & Mean + SD & Mean + SD \\
\hline $83.88+4.79$ & $121.4+6.66$ & $80.16+6.68$ & $35 \cdot 38+3 \cdot 90$ & $39.28+3.73$ & $38.32+3.67$ & $1.033+0.13$ \\
\hline
\end{tabular}

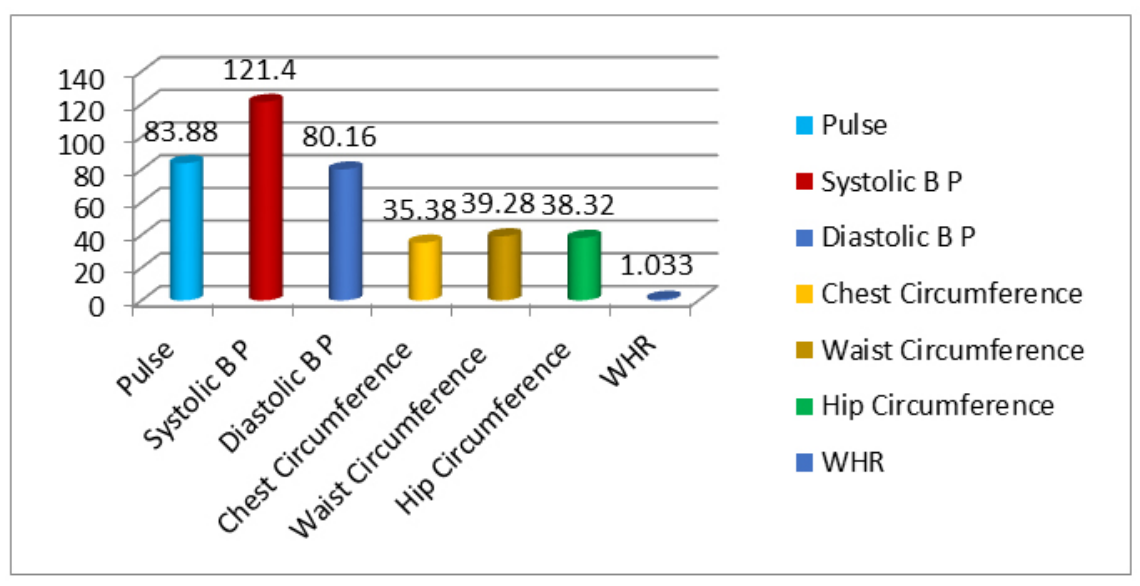

Figure 4: Cardiac and chest, waist and Hip circumference.

Table 4: Nerve conduction velocity $(\mathrm{m} / \mathrm{s})$ of in the obese subject suffering from sciatica pain with normal subjects.

\begin{tabular}{llcccc} 
& & & & & \\
& & & \\
& & & & \\
& & Mean & N & Std. Deviation & Std. Error Mean \\
Pair 1 & NCV in normal subject & 51.7940 & 50 & 3.50489 & 0.49567 \\
& NCV in Obese subject & 48.0200 & 50 & 5.23134 & 0.73982 \\
\hline
\end{tabular}

\begin{tabular}{lccccc} 
& & Paired Samples Correlations & & Correlation & Sig. \\
Pair 1 & NCV in normal subject \& NCV in Obese subject & N & -.007 & 0.961 \\
\hline
\end{tabular}




\begin{tabular}{|c|c|c|c|c|c|c|c|c|c|}
\hline \multicolumn{10}{|c|}{ Paired Samples Test } \\
\hline & & \multicolumn{5}{|c|}{ Paired Differences } & \multirow[t]{2}{*}{$\mathbf{t}$} & \multirow[t]{2}{*}{ df } & \multirow{3}{*}{$\begin{array}{c}\text { Sig. } \\
\text { (2-tailed) }\end{array}$} \\
\hline & & Mean & Std. Deviation & $\begin{array}{c}\text { Std. } \\
\text { Error } \\
\text { Mean }\end{array}$ & $\begin{array}{r}95 \% \text { Cor } \\
\text { Interva } \\
\text { Diffe }\end{array}$ & $\begin{array}{l}\text { fidence } \\
\text { l of the } \\
\text { ence }\end{array}$ & & & \\
\hline & Parameters & & & & Lower & Upper & & & \\
\hline Pair 1 & $\begin{array}{l}\text { NCV in normal subject - } \\
\text { NCV in Obese subject }\end{array}$ & 3.77400 & 6.31761 & .89344 & 1.97856 & $5 \cdot 56944$ & 4.224 & 49 & $0.001^{*}$ \\
\hline
\end{tabular}

Values $<0.05$ is statistically significant * Highly significant 0.001

\section{compsresion of NCV in nornal subject and in obese subject having pain in legs}

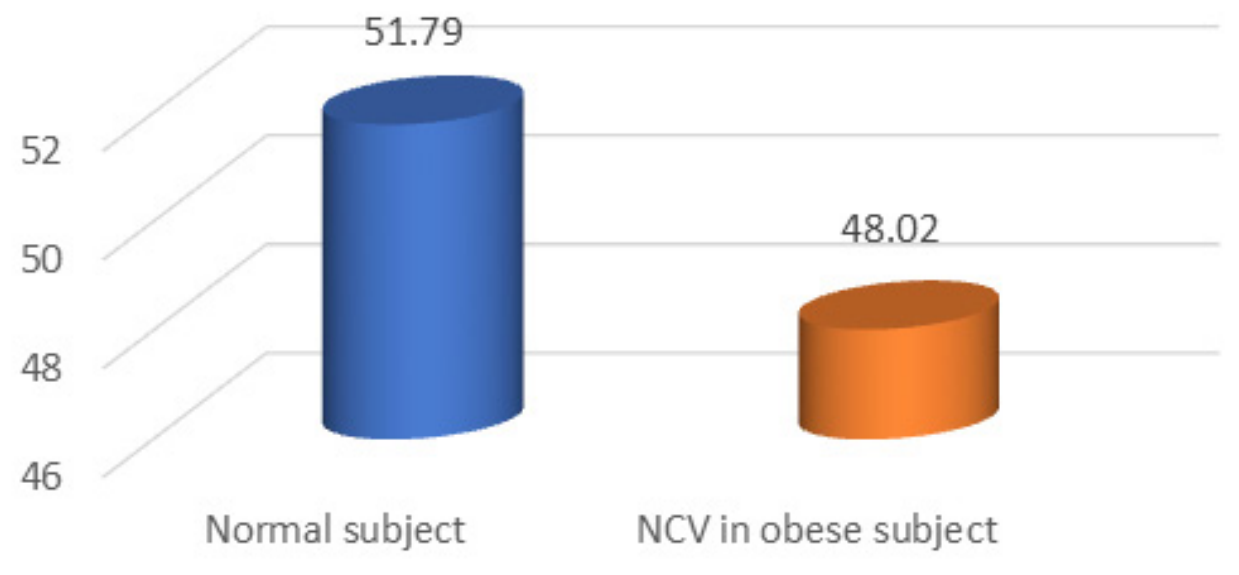

Figure 5: Comparison of Nerve conduction velocity of obese subject having sciatic pain as compared to normal subjects. 